\title{
МОЛЕКУЛЯРНО-ГЕНЕТИЧЕСКАЯ ХАРАКТЕРИСТИКА КОГОРТЫ ПАЦИЕНТОВ С НАРУШЕНИЕМ ФОРМИРОВАНИЯ ПОЛА
}

\author{
Никитина И.Л., Кудряшова Е.К., Фомичева Ю.В., Костарева А.А.
}

ФГБУ «Национальный медицинский исследовательский центр им. В.А. Алмазова» Минздрава РФ, Санкт-Петербург

АКТУАльнОсть: нарушения формирования пола (НФП) можно определить, как врожденную патологию развития, при которой имеет место несоответствие генетического, гонадного, фенотипического и психологического пола. Современные рекомендации по оказанию помощи при данной патологии основаны на мультидисциплинарных подходах к ранней корректной диагностике варианта НФП, в которой все большее значение приобретает поиск генетических основ заболевания и ассоциации с клиническим фенотипом для конкретного пациента. Все перечисленное помогает персонифицировать тактику ведения пациентов с НФП.

ЦЕЛЬ: изучение генетических причин нарушения дифференцировки пола в когорте пациентов с кариотипом 46XY.

МАТЕРИАЛЫ И МЕТОДЫ: включено 27 пациентов в возрасте от 1 мес. до 25 лет с подтвержденным диагнозом НФП с кариотипом 46 ХУ. Стандартное цитогенетическое исследование проводилось на микроскопе LEICA DM LS, оборудованного объективами FLUOTAR 20x/0,40 и 100x/1,30-0,60, автоматической фотонасадкой, цветной камерой Leica DFC 320, блоком светофильтров для флуорохромов FITC и DAPI. Молекулярно-генетическое исследование проведено методом секвенирования нового поколения (NGS) на аппарате HiSeq 2500 (Illumina, США). Биоинформационный фильтеринг результатов секвенирования образцов ДНК проводился с помощью программ: GeneTalk, UGENE, lon Reporter, SIFT, PolyPhen2, PAPI. Патогенность мутаций сайтов сплайсинга оценивалась программой “HSF”. Верификация полученных данных проводилась методом ПЦР-ПДРФ.

PЕЗУЛЬтАТЫ: по нозологическим вариантам распределение пациентов было следующим: дисгенезия гонад - 30\%, синдром резистентности к андрогенам - 18,5\%, проксимальные формы гипоспадии 44,5\%, овотестикулярное НФП - 3,5\%, дефекты стероидогенеза - 3,5\%. Молекулярно-генетическая природа НФП установлена у $39 \%$ детей, среди которых у 55\% которых были выявлены ранее не описанные мутации в генах панели NGS нарушений дифференцировки пола. В сопоставлении с клиническим фенотипом наибольшую патогенетическую значимость имели замены в генах $A R$ (5 чел.), NR5A1 (4 чел.), MAP3K1 (3 чел.), MAMLD (2 чел.), при этом моногенный генез имели 82\%, дигенный генез (мутации 2 генов) - 18\%. В группе проксимальной гипоспадии генетические варианты, расцененные, как значимые, были выявлены лишь в 16\% (2 ребенка). Оценка клинических проявлений при мутации в гене MAMLD, по генетическим базам описанного при гипоспадии, выявила синдромальный вариант пациента с НФП, зарегистрированного в женском поле после двукратной его смены, в ассоциации с тяжелой аномалией мочевой системы и прогрессией хронической болезни почек в первой декаде жизни. У двух пациентов с мутациями в гене стероидогенного фактора NR5A1 имела место семейная форма патологии с выявлением того же генетического варианта у одного из родителей.

ВЫВОдЫ: молекулярно-генетическое исследование при НФП позволяет уточнить генез пренатального нарушения половой дифференцировки, выявляет патогенные варианты у 39\% обследованных в группе с кариотипом 46XY, а у части пациентов, идентифицируя семейные варианты, позволяет осуществить генетическое прогнозирование данной патологии в «ядерных» семьях. 